\title{
THE OCTOBER 1, 1987 WHITTIER NARROWS EARTHQUAKE
}

\section{R. Shepherd*}

\author{
ABSTRACT
}

On October 1, 1987 Southern California experienced the first earthquake for more than sixteen years that had sufficient strength to cause casualties and significant structural damage. The more important results of the event, and of the major aftershock which followed three days later, are summarised with particular reference to the successes in the mitigation of seismic effect which have been achieved both by the application of more stringent code requirements, in the case of new buildings, and by strengthening procedures in the case of existing ones.

\section{THE EARTHQUAKE}

The Whittier Narrows event is one of the more moderate sized earthquakes which have occurred in Southern California this century. The October 1, 1987 tremor occurred at 7.42 a.m. local time and was assigned a Richter Magnitude of 5.9 after reconsideration of an earlier assessment of 6.1. In terms of energy release it was an order of magnitude smaller than the 1971 Symlar earthquake but was larger than either the $1986 \mathrm{Palm}$ Springs or 1984 Morgan Hill event. The epicentre was to the west of Whittier (Figure 1), more nearly at Rosemead. The focus is thought to be some $14 \mathrm{~km}$ below the ground surface. No surface rupture has been located. The unconsolidated sediments are many thousands of feet thick in this part of the Los Angeles Basin which features a continuous shortening of the distance between the Palos Verdes Peninsula and the San Gabriel mountains. The general pattern of identified faults comprises thrust faults to the north and strike/slip ones to the south. Initially, it was thought that the October 1 event had occurred on the Whittier fault which is known to be steeply dipping but studies based primarily on the aftershock characteristics resulted in modification of this view. Although the aftershock sequence was relatively small, there being about thirty shocks equal or greater than Richter Magnitude 3 compared with more than three times that number of equivalent size after the 1986 Palm Springs main shock, it was large enough for adequate analyses to be undertaken. The main shock was

* University of California, Irvine, U.S.A. established to be on a shallow angled, north dipping plane with east/west strike, clearly not consistent with the whittier fault. The main aftershock of Richter Magnitude 5.5 on october 4 had an epicentre a few miles to the west of the october 1 and was associated with a right lateral strike/slip movement on a steeply dipping plane but again not compatible with the characteristics of the Whittier fault. Consequently it has been concluded that the October 1 event must have occurred on a previously unidentified fault. This has implications for the safety of downtown Los Angeles which previously has been judged not to be in immediate proximity 
to an identified fault and, therefore, to be relatively safe with respect to the potential for excitation from a small but close fault movement.

\section{GROUND MOTION}

The California Strong Motion Instrument project and the U.S. Geological Survey program have succeeded in the installation and operation of instrumentation over the last fifty years to the extent that more than five hundred stations provided records of Whittier Narrows' earthquake response. Some two hundred public buildings had at least one strong motion instrument installed. Horizontal ground level motion peaks of $63 \% \mathrm{~g}$ at Whittier, of $40 \% \mathrm{~g}$ at $6 \mathrm{~km}$ from the epicentre, of $30 \% \mathrm{~g}$ at $8 \mathrm{~km}$ distance and of $20 \% \mathrm{~g}$ at $20 \mathrm{~km}$ distance were recorded. An atypical peak of $60 \% \mathrm{~g}$ was measured at Tarzana, some $40 \mathrm{~km}$ from the epicentre, with a predominant period of $3 \mathrm{~Hz}$ and a vertical component of $9 \% \mathrm{~g}$. Generally the strong shaking appears to have lasted for only some four seconds. Peak roof accelerations were frequently found to be somewhat larger than those at ground level as would be expected in flexible buildings. The peak horizontal accelerations at ground level in the downtown Los Angeles area appear to have been between $10 \%$ and $20 \% \mathrm{~g}$. The attenuation clearly was not uniform in that the shaking was greater in those areas to the east and west of the epicentre than in those to the north and south. Also the variation of peak acceleration with distance from the epicentre in any one direction was erratic as would be expected wher local site considerations are taken into consideration.

A large number of strong motion records are available (1) not only of ground response but also of the motions of various parts of buildings, dams, bridges and other structures and these will undoubtedly provide the opportunity for extensive future analyses.

\section{BUILDING RESPONSE}

The emotional response to catastrophic events, such as damaging earthquakes, tends to obscure the engineering assessment that the lessons learned from studying earthquakes (2) over the last half century have been heeded to a large degree and as a consequence the toll of casualties, both human and constructed facilities, was gratifyingly small when judged in the context of the severe ground motion. Nevertheless, damage amounting to some US\$M400 was sustained as a result of the october 1 and October 4 events.

As is inevitable in any area developed over some two hundred years, a wide range of building types and stanoards was tested. Some newer structures behaved disappointingly but, overall, there is positive evidence to support the contention that code provisions are serving their objective in minimizing casualties and preventing total building collapse (3).

In anticipation that continuing improvements will be possible, based on critical examination of past performance, specific reference is made below to a selection of unrepresentative buildings, namely those which suffered relatively spectacular damage.

Many pre-code buildings in the area of severest shaking either collapsed or were weakened to the point that occupation is unsafe. There is probably little more to be learned from a study of most of these than has been thoroughly documented on previous occasions. Many downtown Whittier commercial buildings dated back to the early part of this century and, although extensively architecturally remodelled, had only rarely experienced any structural strengthening.

Clearly the greatest benefit is to be gained from studying the behaviour of those buildings which responded unexpectedly, as information recovered in such cases may well form the basis of more successful earthquakeresistance practices.

\section{UNREINFORCED MASONRY BUILDINGS}

The City of Los Angeles has a well deserved reputation for innovation in attempts to reduce seismic hazards on existing structures. A parapet ordinance (4), instigated almost forty years ago, addressed the problem of parapets of inadequate strength on faces of buildings adjoining public access areas. In 1981 the City adopted a seismic safety ordinance (5) requiring the upgrading of many pre-code unreinforced masonry buildings to predetermined engineering standards. Many other civic authorities have followed the Los Angeles City example. None of the prcograms have yet been completed but sufficient progress has been made to provide, particularly in Los Angeles City itself, a data base of adequate size to enable worthwhile assessment to be made of the effectiveness of the retrofitting standards.

Specific details on which attention is being focused in the strengthening process include footings; wall infills, wall braces and shear walls; vertical load-carrying members; floor and ceiling diaphragms; wall tension anchors and shear bolts; parapet bracing and diaphragm opening reinforcement (6).

The Los Angeles City program was originally scheduled to be completed in 1995 but was accelerated following the september 19, 1985 Mexico earthquake and completion is now planned for 1990. At the time of the Whittier Narrows' event, the upgrading program was approximalely one third completed. One thousand buildings had been totally strengthened, fifteen hundred partially strengthened, and either plans had been filed or work was in hand for a further thousand.

A total of more than eight thousand buildings were inspected in the City of Los Angeles immediately following the cctober 1 and 4 events. As is shown in Table 1 about a quarter were unreinforced masonry (URM) . 
TABLE 1 - City of Los Angeles buildings inspected (source E. Schwartz, L.A. Dept. of Building \& Safety)

$\begin{array}{cl}\text { All } & \text { Unreinforced } \\ \text { Buildings } & \text { Masonry Bldgs }\end{array}$

\begin{tabular}{lcc} 
No damage & 5416 & 1583 \\
Damaged & 2558 & 520 \\
$\begin{array}{l}\text { Vacated or } \\
\text { partially vacated }\end{array}$ & 294 & 116 \\
\cline { 2 - 3 } & 8268 & 2119
\end{tabular}

of the unstrengthened and partially strengthened URM buildings $31 \%$ were significantly structurally damaged, whereas only $20 \%$ of the strengthened URM buildings suffered to this degree. The figures for the buildings damaged so severely that they had to be vacated were even more indicative of the effects of retrofitting. Only 2\% of those buildings which had been fully strengthened had to be vacated whereas of the total group of unstrengthened and partially strengthened buildings examined, 6\% had to be vacated.

Several characteristic failure patterns were confirmed in unstrengthened URM buildings and were identified in strengthened ones.

One problem which clearly persists is that of weak parapets in position not covered by the earlier parapet ordinance. Such parapets on walls adjoining other buildings are liable to collapse and to thereby cause damage to other property (Fig. 2). A second ongoing problem is that of inadequate bond between layers of bricks in the vertical plane resulting in peeling off of outer withes (Fig. 3).

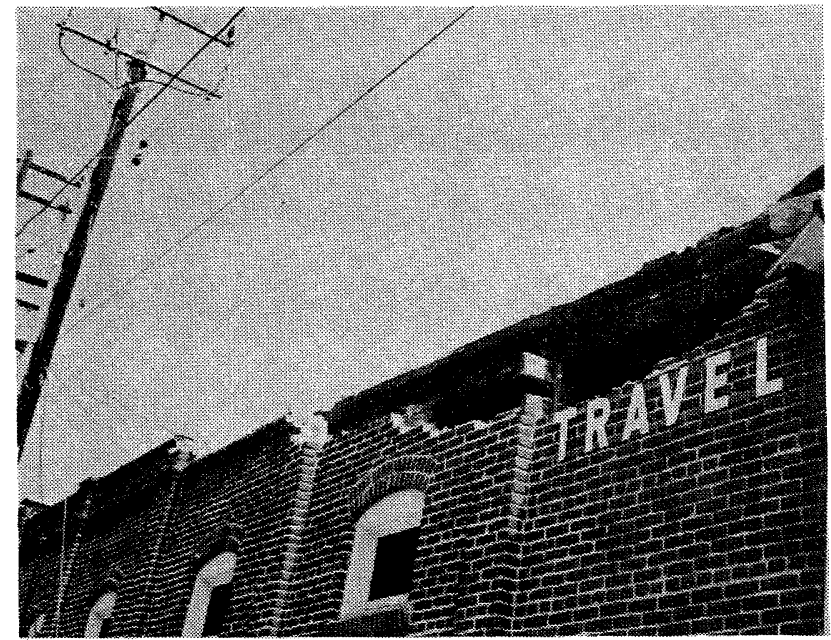

FIG. 2 - Collapsed parapet, to left, and upper part of bearing wall, to right

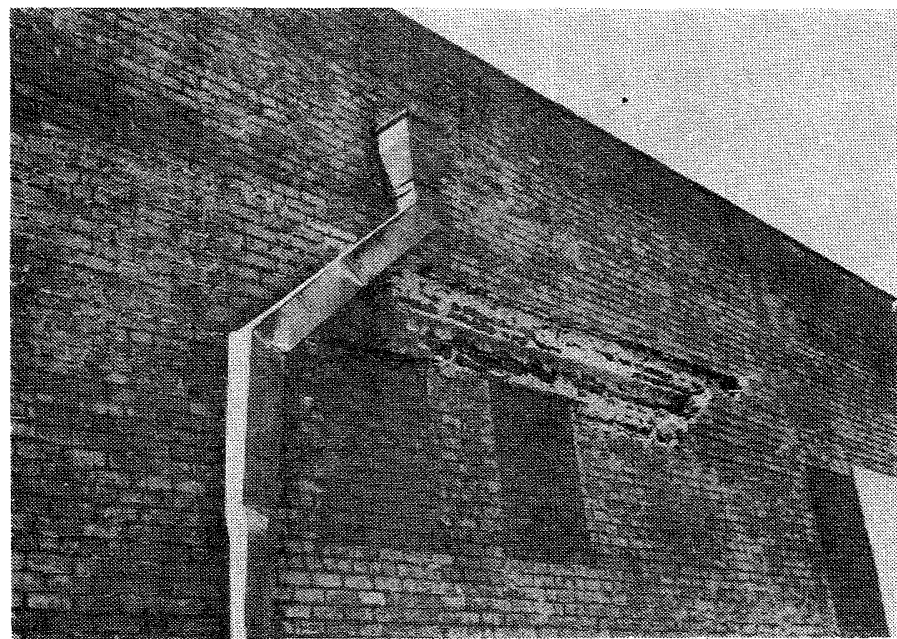

FIG. 3 - Loss of outer withes of bricks

Some walls are susceptible to out-of-plane bulging, again indicating deficient lateral restraint (Fig. 4).

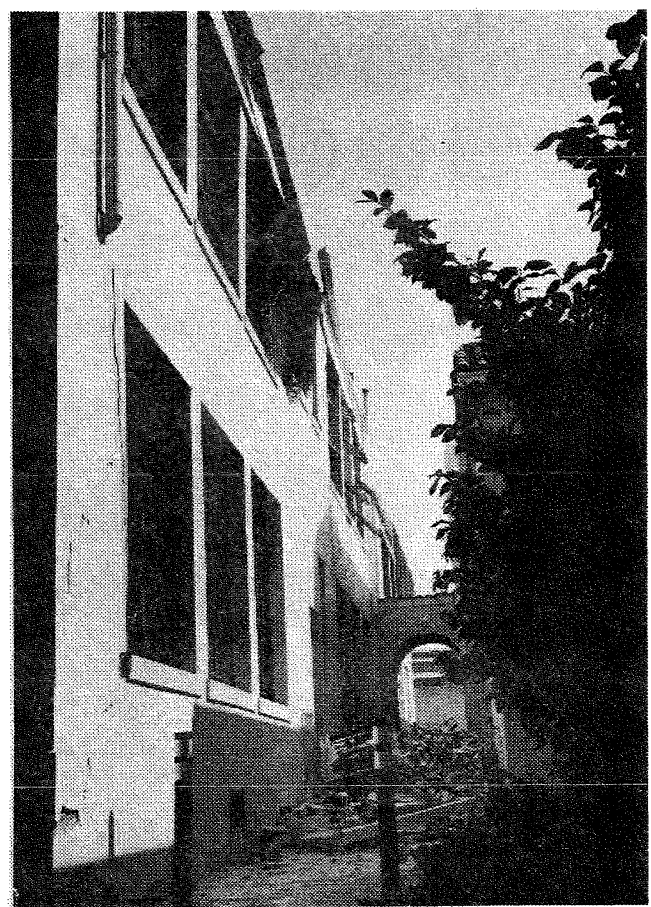

FIG. 4 - Bulging and collapse as a result of inadequate lateral restraint

A recurrent problem with strengthened buildings is manifested by cracks occurring in the masonry at the corners of the building consistent with the floor and ceiling diaphragm having exerted horizontal force to push the wall outwards (Fig. 5). This can be ascribed to flexibility in the shear connectors with consequent inability to transfer the diaphragm inertia forces to inplane wall loads without significant slipping.

Unanticipated distress in brick piers 


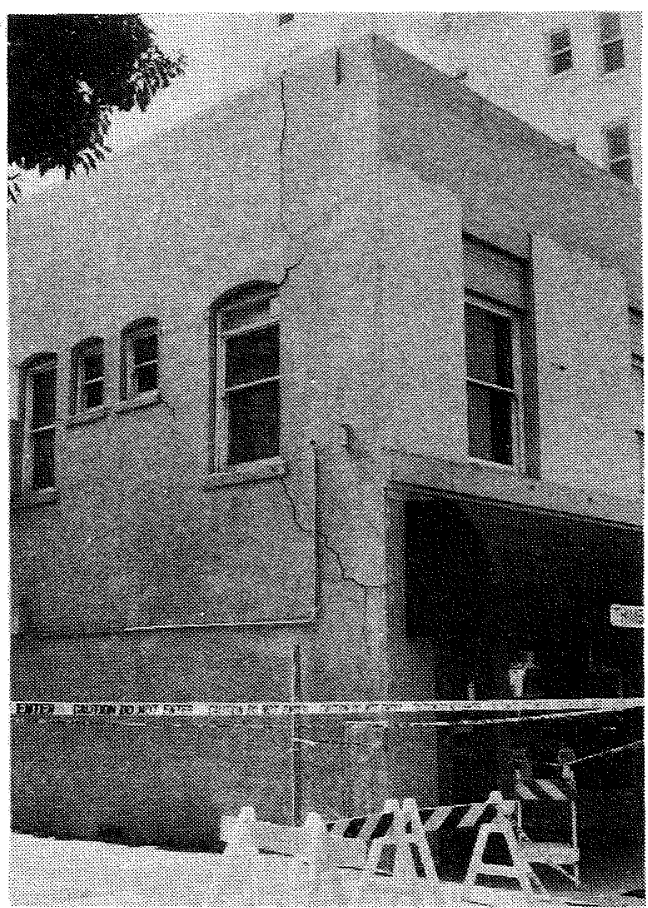

FIG. 5 - Front wall pushed outwards by diaphragm inertia forces

and brick spandrel beam zones was recorded (Fig. 6) Causes for these problems have yet to be agreed and, consequently, remedies are yet to be found.

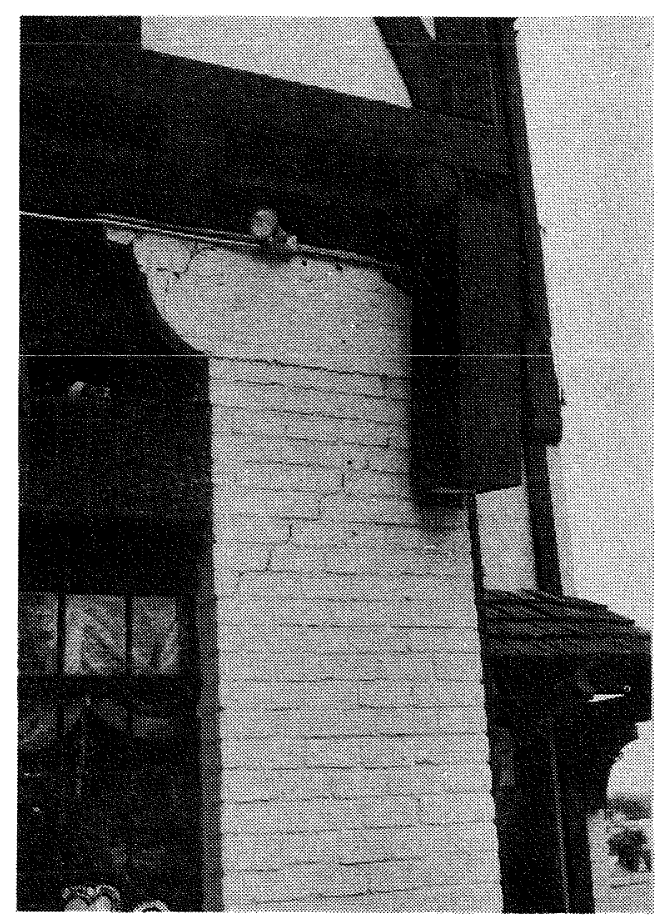

FIG. 6 - Failed brick pier
Many failures in upper level URM walls occurred where only two withes of bricks existed. Such configurations probably proved particularly vulnerable to sharp peak accelerations.

The brittleness of plaster results in it cracking at relatively low strains and consequently considerable care is necessary when interpreting surface plaster cracks as indicative of the state of the underlying structural component. In many cases it was noted that after the Whittier Narrows' earthquake that cracked plaster did not necessarily imply cracked masonry beneath.

It seems probable that when the effects of this most recent damaging tremor on both the strengthened and the original URM buildings have been analysed some modification of the existing retrofitting ordinanace will be proposed. In this respect it is perhaps fortunate that the existing strengthening standards could be subjected to a genuine field test before the program was substantially completed.

\section{ENGINEERED BUILDINGS}

The likely deficiencies of structures designed to earlier codes have long been recognised and so it was no surprise that some buildings constructed between twenty and thirty years ago suffered significant damage. One such complex was that on the campus of the California state University at Los Angeles, some $6 \mathrm{~km}$ from the epicentre, at the intersection of the Long Beach and 10 freeways. Eighteen buildings of between three and nine stories exist on the site. Substantial structural damage was sustained by beams, columns and shear walls, no doubt prompted by features currently recognised to be undesirable such as flexible lower stories and asymmetrical footprints.

One student was killed when a $3.65 \mathrm{x}$ $2.3 \times 0.15 \mathrm{~m}$ precast lightweight concrete panel fell on her after failure of the connections to the supporting car park structure (Fig. 7). The surviving 334

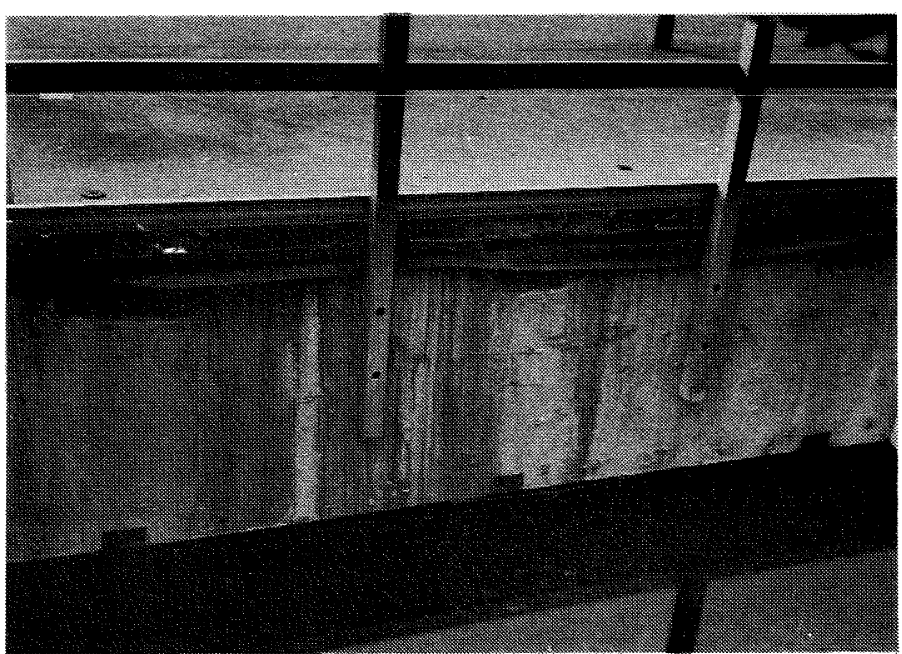

FIG. 7 - Position from which panel fell, killing student. Railing added after accident. 


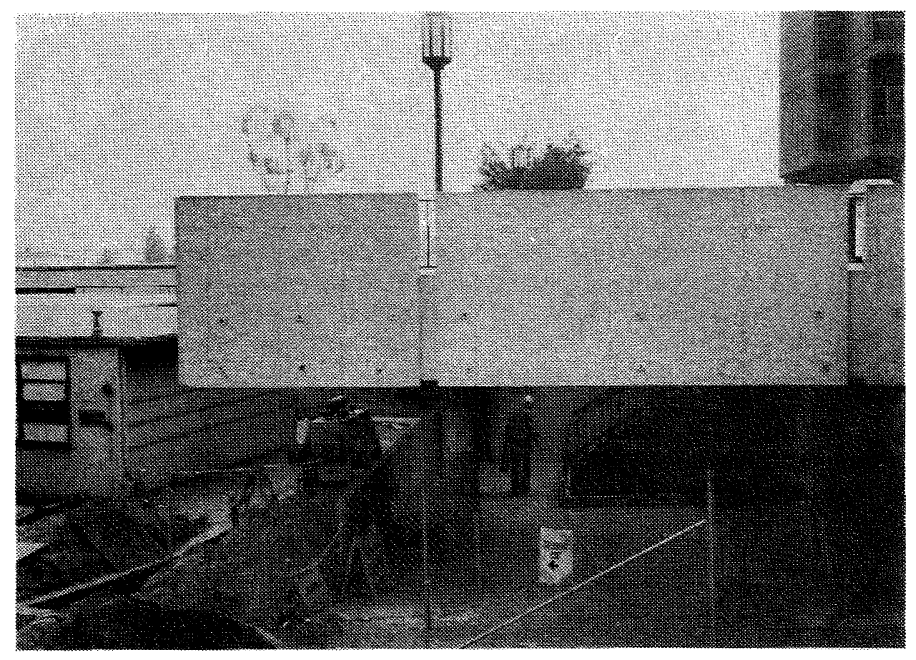

FIG. 8 - Panel connection strengthened by addition of bolts

similar panels have had their fastening reinforced by the addition of $2.54 \mathrm{~cm}$ diameter bolts (Fig. 8).

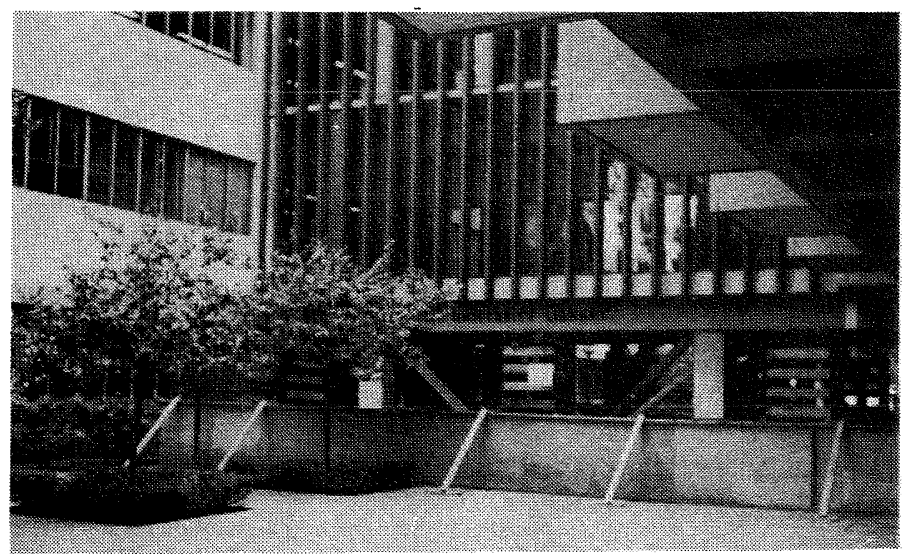

FIG. 9 - California State University, Los Angeles, Library Bridge

A somewhat unusual structure, the Library Bridge (Fig. 9), connecting the main builaings, suffered extensive damage. Weighing some $4450 \mathrm{kN}$ and of plan dimensions $18 \times 7.6 \mathrm{~m}$ the bridge has a centre span of almost $8 \mathrm{~m}$. It is supported on four columns each $0.61 \mathrm{~m}$ square and having 4 \#18 (56 mm diameter) bars as main reinforcement. The ties are \#3 (10 mm diametex) bars at $0.46 \mathrm{~m}$ pitch and, as might have been expected, extensive shear cracking occurred (Figs. 10 and 11). The columns extend downwards different distances, the shortest being $3 \mathrm{~m}$ and the longest $7.3 \mathrm{~m}$. This may well explain the indication of torsional excitation exhibited by one of the columns.

The eight storey Administration building is supported at ground level by twelve columns and two shear walls. It is instrumentated with sixteen strong motion channels

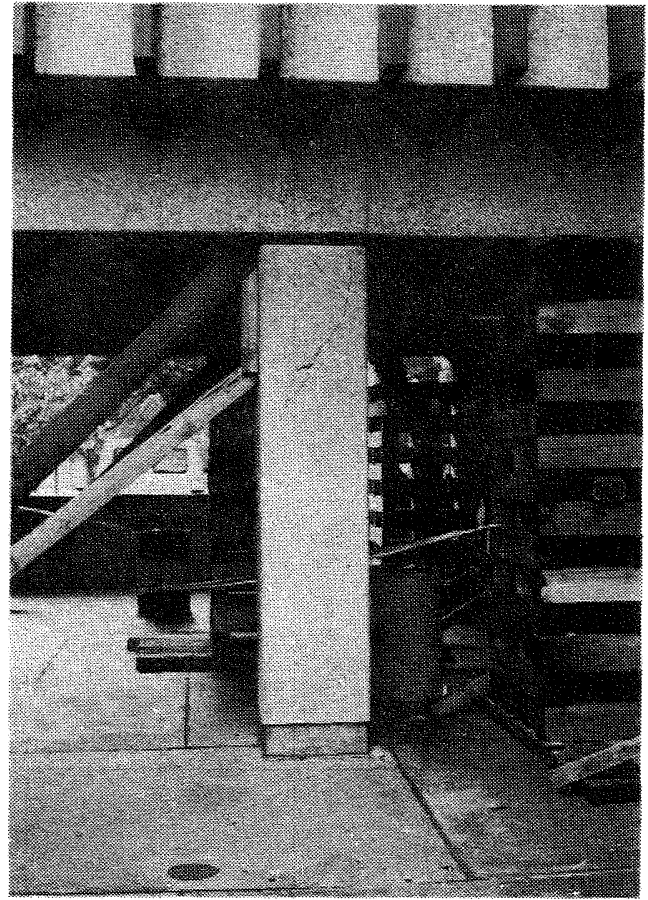

FIG. 10 - Cracked col.umn in Library Bridge

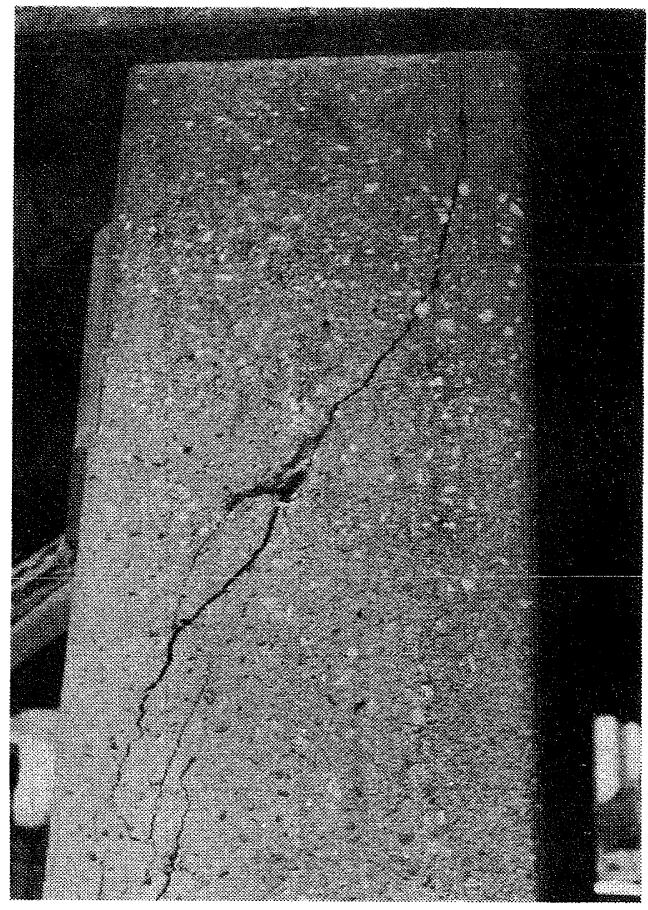

FIG. 11 - Close-up of cracked column shown in Fig. 10

and worst case acceleration peaks of $39 \% \mathrm{~g}$ (E-W) at the base, $48 \% \mathrm{~g}(\mathrm{~N}-\mathrm{S})$ at the roof, and $53 \% \mathrm{~g}$ (vertical) at the second level were recorded. One support column was badly cracked (Fig. 12) and promptly 


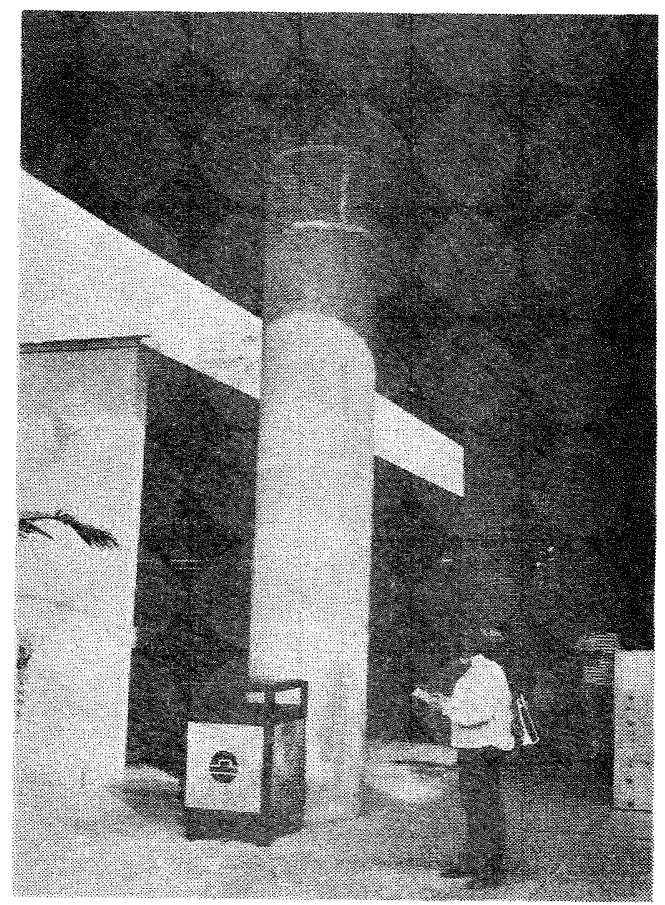

FIG. 12 - Epoxy repaired column at base of Administration Building

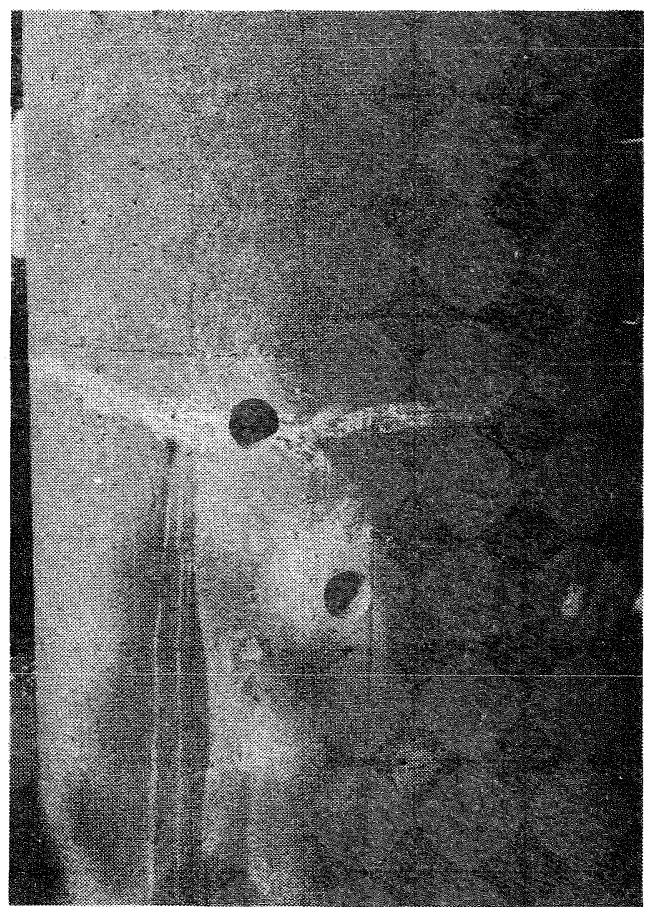

FIG. 13 - Cores taken to check effectiveness of epoxy repair

repaired using epoxy (Fig. 13). Similar repairs were undertaken on shear cracks which formed in beams in the adjoining parking structure.

The nine storey physical science building suffered extensive cracking of the shear walls and severe non-structural damage from broken chemical containers, a flash fire and flooding from broken water mains in the upper floors.

The disruption to this 22,000 student campus necessitated its closure for a week. It is estimated that damage exceeding \$M20 was sustained.

\section{TILT-UP BUILDINGS}

Much use is made of tilt-up concrete slab construction for commercial and industrial buildings in Southern California. Buildings of this configuration fared badly in the 1971 San Fernando tremor (7) as a result of which improvements were required in many details. In the last sixteen years designers have tended to require more complex layouts with greater use of dry panel joints, more reinforcement bar welding and less continuity of inplane walls. These changes resulted in not only a reaffirmation of many of the 1971 problems but some additional ones which manifested themselves as failures in corners and in unintended shear walls, which served to collect loads in components of inadequate capacity. The considerable amount of damage must be of concern, since in this most recent earthquake there were no more than four or five seconds of very strong ground shaking.

A few cases have been reported of excessively heavy damage to buildings designed and constructed within the last ten years. Inevitably, the question must be asked, which of the possibilities of inadequate code provisions, design errors or construction faults, contributed to the poor behaviour. It is not yet possible to answer this comprehensively but the generally satisfactory response of the large majority of newer buildings supports the view that the code provisions are adequate for at least a large number of typical constructional forms.

\section{NON ENGINEERED BUILDINGS}

A very common form of construction used in single family houses and two and three storey apartment buildings in southern California involved concrete floor slabs, timber framed walls covered with stucco and a light roof. The incompatibility of the rigid plaster stucco and the flexible timber frame frequently leads to extensive cracking of the stucco under siqnificant lateral loads and, indeed, cracked stucco was a feature of much superficial damage sustained in the Whittier Narrows' earthquake (Figs. 14 and 15). Of greater structural significance, was the collapse of some vertical load carrying members, such as verandah posts (Fig. 16), where inadequate framing action was generated, and the shifting of buildings horizontally at foundation level, with consequent fracturing of the service connections in some instances. Although the use of unreinforced brick chimneys is much less prevalent than in the past, where these existed a large proportion collapsed.

The common practice of providing parking underneath living quarters frequently results in a building being severely torsionally unbalanced as well as having a 


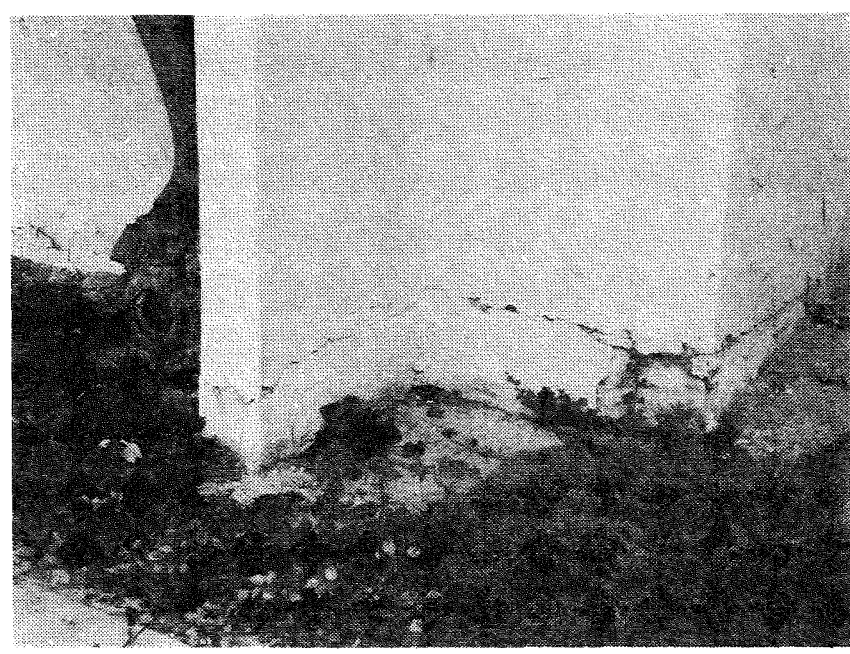

FIG. 14 - Cracked stucco at base of wall of Whittier apartment building

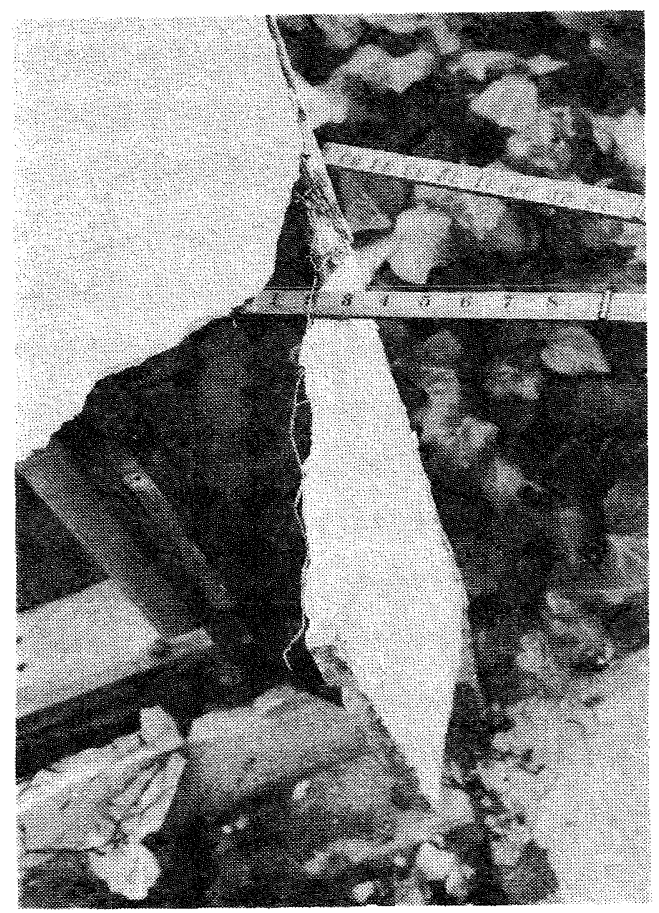

FIG. 15 - Fractured stucco where airconditioning unit had broken loose from wall of whittier apartment building

flexible bottom storey (Fig. 17). This resulted in some buildings being damaged to the extent they were judged unsafe for occupation (Fig. 18).

\section{SPECIAL STRUCTURES}

of considerable historical interest was the behaviour of the San Gabriel Mission. This 1791 masonry bearing wall structure had lost its original bell tower in the 1813 earthquake but, after repairs, had survived successive seismic actions until suffering
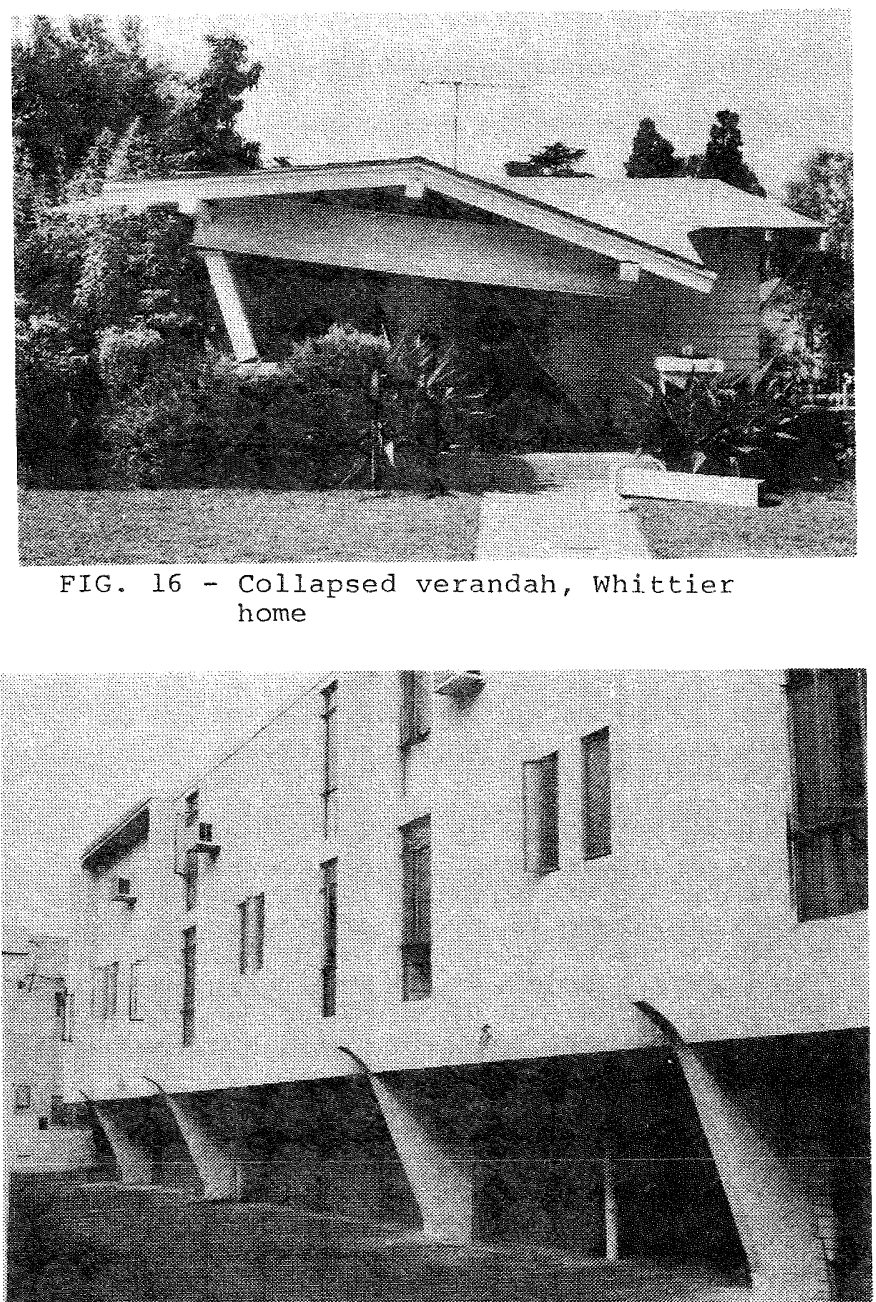

FIG. 17 - Parking bays under apartment building (Plywood panels added to avoid collapse of damaged support walls)

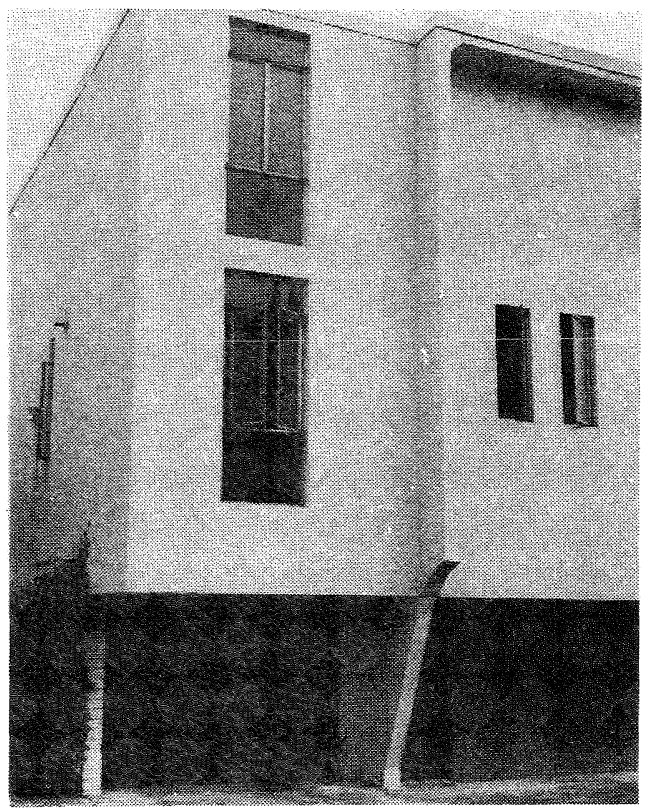

FIG. 18 - Fractured support wall at ground level, left hand end of building shown in Fig. 17. 
severe cracking and indeed minor collapse of some portions in the october 1 and 4 events. It is not clear whether the cost of restoring the Mission on this occasion will be considered to be justified.

The closing of two of the main freeways for some twenty hours following the october 1 event caused severe disruption and served to confirm the importance of the survival of the freeway bridge system. Claims were made that the retrofitting programme undertaken by the California Department of Transportation in recent years prevented much greater loss of services of overpasses, but the damage to the 650 freeway bridge crossing the Interstate 5 freeway took the form of extensive shear cracking of the five column reinforced concrete support bent positioned along the centre divider. Each column is $3.7 \mathrm{~m}$ high and of $1.22 \times 0.9 \mathrm{~m}$ section with $1.5 \mathrm{~m}$ deep beams across the top and bottom. Heavy timber shoring was installed to relieve some of the load on the columns before the freeway was reopened. It is not at all clear that the retrofitting so far undertaken, which involves almost exclusively the anchoring of spans to piers and abutments in an attempt to avoid dropping a span, will prove to be adequate in a future, larger, earthquake when most probably the characteristic damage mode will once more be shear failure of column members.

Car park buildings having large spans and relative few load carrying walls tend to be vulnerable to earthquake loading. A four storey structure of this type in Whittier lost its top floor in the october 1 earthquake and then collapsed completely in the October 4 shake (Fig. 19). It is notable that a nearby similar structure with spiral wound columns survived both events.

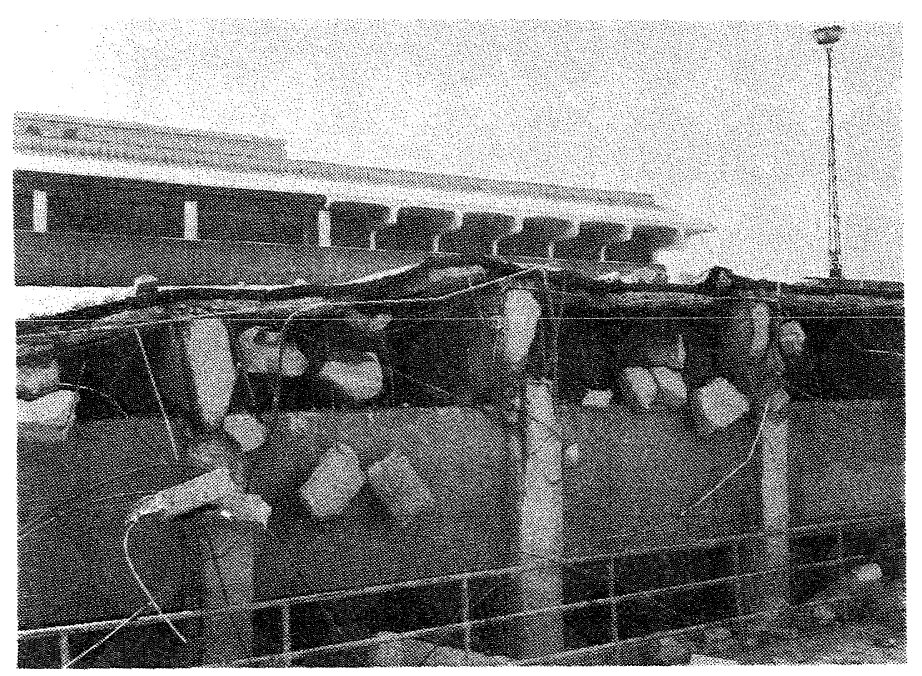

FIG. 19 - Collapsed car parking building in Whittier

OTHER ASPECTS

Telephone services were grossly over- loaded for many hours after the main shock to the extent that it was extremely difficult to complete a call. Electrical power connections were interrupted, several thousand consumers being without supplies for much of the day. Problems encountered with gas supplies included the inability of many homeowners to turn the supply on again, after it had been cut off by the seismically triggered shut-off valves where these had been installed for that purpose, and the difficulty in relighting pilot flames in water heaters after homeowners had turned off the supply, in the majority of cases unnecessarily, immediately following the earthquake. Some gas and water leaks were reported and some twenty fires required attention. It was generally agreed that the emergency services performed satisfactory but it was appreciated that the disaster was not a major one of the magnitude possible, and indeed likely, in southern california within the next. thirty years.

A recently recognized hazard facing rescue and clean-up teams, is the presence of asbestos fibre dust where this has been released by damage to various forms of insulation. Strict precautions invoked to minimize the health risk to construction workers is undoubtedly hindering repair work.

\section{COST FACTORS}

It is estimated that the Whittier Narrows' earthquake has caused damage amounting to about \$US\$M400. About a quarter of this comprises damage to public facilities, the rest is classified as private damage. Some seventeen thousand residents have applied for disaster relief which mav take the form of $3 \#$ deferred payment loans to homeowners as well as grants and tax deferrals.

Grants of up to US\$10.000 from the State and US\$5.000 from the federal government are available to individual homeowners. renters or small businesses to obtain clothing and furnishings. $\$ M 15.3$ has been made available to the California state University to repair the Los Anceles campus.

It is not clear to what extent earthquake insurance will mitigate the losses experienced. Earthquake insurance is a matter of personal choice in california and costs around $\$ 2 /$ year per $\$ 1,000$ with, typically, the homeowner being responsible for the first $10 \%$ of repair costs. It is believed that only about $15 \%$ of Californian homeowners currently have earthquake insurance.

\section{SUMMARY}

The whittier Narrows' earthquake is an example of those expected to occur every ten or twenty years somewhere in the Los Angeles basin. It was not a major event judged either in terms of energy release or by economic loss. Most of the evidence supports the contention that the earthquake mitigation efforts of the last fifty years, as reflected in the building codes, have provided progressivelv improved protection. 
Sufficient damage was sustained to enable the learning from earthquake process to benefit from careful analysis of the failures which did occur. The retrofitting of existing structures to increase seismic resistance appears to be meeting with some success in such areas as the pre-code unreinforced masonry buildings. Refinements of the strengthening procedures are likely as a result of the experiences gained in this earthquake.

\section{REFERENCES}

1. CSMIP Strong-Motion Records from the Whittier, California, Earthquake of 1 October 1987; California Department of Conservation, Division of Mines and Geology, Sacramento; Report OSMS 87-05, 1987 .

2. Scholl, Roger E. (Ed.) "Reducing Earthquake Hazards; Lessons Learned from Earthquakes", Earthquake Engineering Research Institute, 1986.

3. Uniform Building Code. Internationai Conference of Building Officials, Whittier, California, 1985.

4. Los Angeles Municipal Code, "Parapet correction program", Ordinance No. 94,970 approved 1949 .

5. Los Angeles Municipal Code, "Earthquake hazard reduction in existing buildings", Ordinance No. 154,807 approved 1981.

6. Lee, D.M. and Shepherd, R., "Hazardous Buildings: Aspects of the Los Angeles Earthquake Problem". Earthquake Engineering and Structural Dynamics, 1984, Vol. 12, No. 2, pp. 149-167.

7. Jennings, P.C. (Ed.), "Engineering Features of the San Fernando Earthquake of February 9, 1971". Report EERI 71-02, California Institute of Technology, 1971. 